\title{
Descrição de Sycorax bahiensis sp. nov. (Diptera, Psychodidae) do Brasil
}

\author{
Freddy Bravo
}

Departamento de Ciências Biológicas, Universidade Estadual de Feira de Santana. Avenida Universitária, 44031-460 Feira de Santana, Bahia,Brasil.E-mail: fbravo@uefs.br

\begin{abstract}
Description of Sycorax bahiensis sp. nov. (Diptera, Psychodidae) from Brazil. Sycorax bahiensis sp. nov. from Bahia is described and illustred.
\end{abstract}

KEY WORDS. Bahia, new species, taxonomy.

\begin{abstract}
São conhecidas trinta e duas espécies de Sycorax Curtis, 1839 em todas as regiões zoogeográficas (Јвzек 1999), sendo sete neotropicais (TonNoIr 1929, BARRETTO 1956, Young 1979). Somente duas espécies foram descritas do Brasil, S. assimilis Barretto, 1956 e S. satchelli Barretto, 1956, ambas do estado de São Paulo, sudeste do Brasil (BARRETTO 1956). Neste trabalho, é descrita uma nova espécie de Sycorax da Bahia, nordeste do Brasil.

Os exemplares estudados foram tratados com solução aquosa de hidróxido de potássio (KOH), montados em lâmina permanente e depositados na Coleção Entomológica da Universidade Estadual de Feira de Santana (CUFS), Feira de Santana, Bahia. A terminologia utilizada para as nervuras alares é a proposta por Colless \& MCAlpine (1991) e as demais terminologias seguem McAlpine (1981).
\end{abstract}

\section{Sycorax bahiensis sp. nov. Figs $1-12$}

Material-tipo. Holótipo macho. BrasiL, Bahia: Santa Terezinha (Serra da Jibóia, $3 \mathrm{~km}$ de Pedra Branca, 12²51'S, 39²8' $\mathrm{W}$, 800 m, mata higrófila), 01.IV.2001, I. Castro leg. (CUFS). Parátipo: 1 macho, mesma localidade e coletor, 14.X.2002 (CUFS).

Etimologia. O nome da espécie é alusivo ao estado onde os espécimes foram coletados.

Diagnose. Olhos compostos sem ponte ocular. CuA não alcançando a margem da asa. Terminália masculina (Figs 1012): gonóstilos com uma cerda apical robusta; cerco mais longo que largo com micropilosidade apical; parâmero complexo, constituído por três pares de braços; apódema ejaculador longo e, lateralmente, largo na base.

Holótipo macho. Comprimento do corpo, 1,31 mm. Cabeça subcircular (Figs 1-3); clípeo e labro compridos (Fig. 1). Premento triangular, esclerotinizado, com cerdas (Fig. 2). Braço posterior do tentório, diagonal em relação ao eixo dorsoventral (Fig. 3). Palpo maxilar com quatro segmentos; comprimento relativo dos segmentos do palpo: 1,0:0,85:0,65:1,05 (Fig. 7). Antena com 13 flagelômeros; escapo pequeno subpiramidal e pedicelo subesférico, maior que o escapo (Fig. 4); flagelômeros basais cilíndricos (Figs 4 e 5); primeiro flage- lômero o dobro do comprimento do segundo (Fig. 4); último flagelômero com pequeno apículo separado por sutura (Fig. 6); ascóides perdidos. Tórax com o metaepisterno estreito, visível apenas posteriormente; fragma pós-notal curto (Fig. 8). Comprimento da asa, 1,31 mm; largura máxima, 0,54 mm; r-m presente; $\mathrm{m}$-cu presente; $\mathrm{CuA}$ curta, não alcançando a margem da asa (Fig. 9). Tergito 9, gonocoxitos, gonóstilos e parâmeros com pilosidade; cercos e superfície ventral do esternito $10 \mathrm{com}$ micropilosidade apical (Figs 10-12). Tergito 9, em vista dorsal sub-retangular (Fig. 12) e em vista lateral subtriangular (Fig. 10). Cercos compridos, estreitos lateralmente, (Figs 10, 12). Esternito 9 semelhante a uma estreita banda na parte anterior da terminália (Fig. 11). Gonocoxitos subcilíndricos articulados medialmente ao esternito 9 (Figs 10, 11). Gonóstilos subcilíndricos, estreitos em relação aos gonocoxitos, com uma cerda apical espessa, de comprimento igual a metade do comprimento do gonóstilo (Figs 10, 11). Esternito 10 de formato oval, mais longo que largo (Fig. 12). Edeago simétrico (Fig. 11). Complexo parameral composto por três pares de braços; o primeiro, o mais interno, esclerotinizado, com ponte estreita acima do apódema edeagal e ápice pontiagudo (Fig. 11); o segundo par de braços do complexo parameral, menor, mais externo e menos esclerotinizado que o primeiro, suboval (Fig. 11); o terceiro par de parâmeros, mais compridos que o primeiro e segundo parâmeros, alcançando o ápice do gonóstilo, mais longos que largos, com cerdas no ápice (Figs 10,11). Apódema ejaculador comprido, largo basalmente (Figs 11, 12). Ponte gonocoxal ausente.

Discussão. As espécies de Sycorax foram divididas em três gêneros por Duckнouse (1972), Sycorax s. s., Aposycorax Duckhouse, 1972 e Parasycorax Duckhouse, 1972. Essa classificação não foi adotada por Jеzeк (1999) na lista das espécies de Sycorax do mundo, considerando apenas o gênero Sycorax. Neste trabalho foi adotada a proposta de Jеzeк (1999). As espécies de Sycorax da região neotropical foram descritas da América do Sul, sendo uma do Chile: S. chilensis Tonnoir, 1929, quatro da Colômbia: S. andicola Young, 1979, S. colombiensis Young, 1979, S. fairchildi Young, 1979 e S. trispinosa Young, 1979, e duas do Brasil: S. assimilis e $S$. satchelli. 


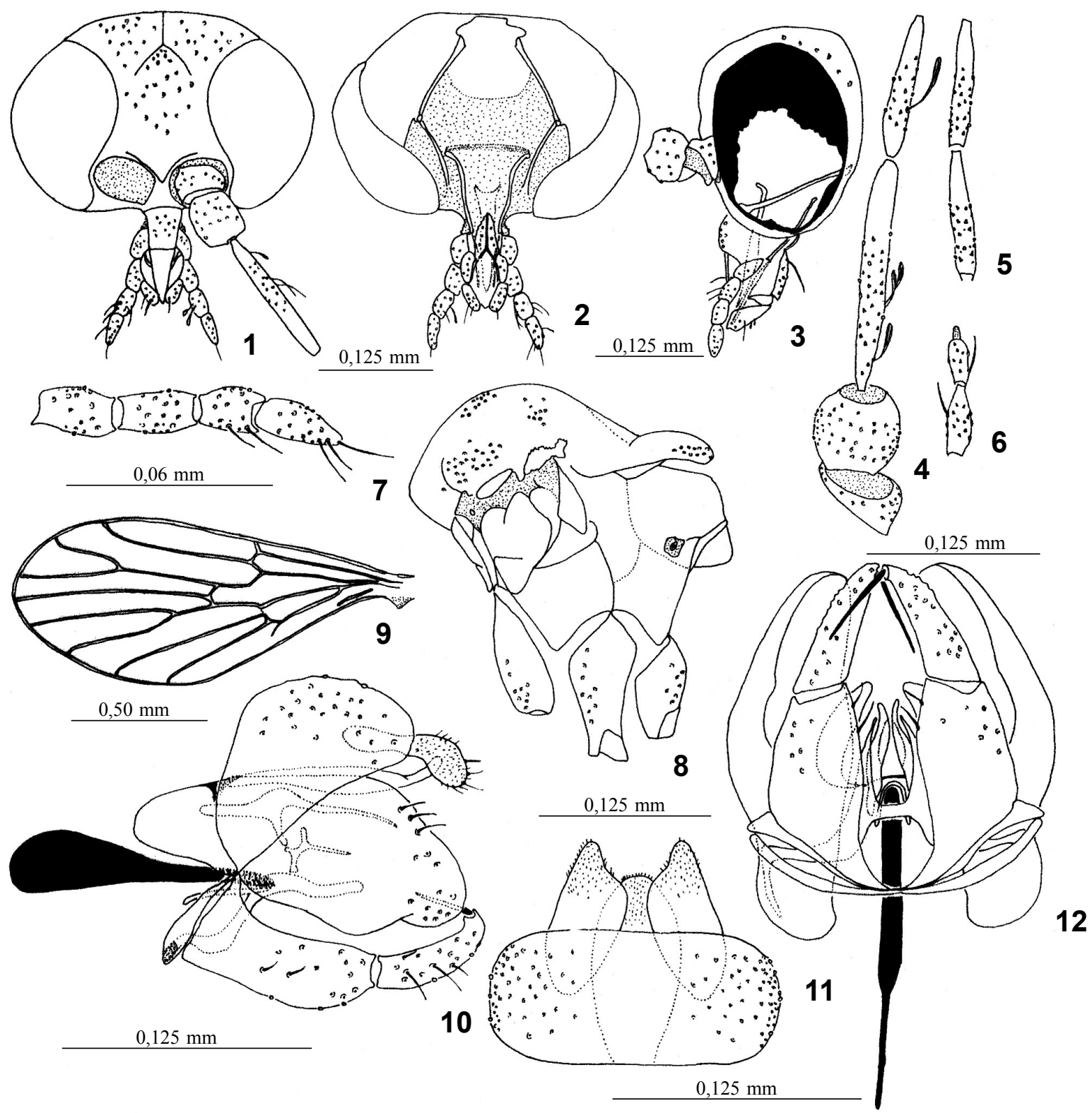

Figuras 1-12. Sycorax bahiensis sp. nov., holótipo. (1) Cabeça, anterior; (2) cabeça, posterior; (3) cabeça, lateral; (4) escapo, pedicelo e dois primeiros flagelômeros; (5) $5^{\circ}$ e $6^{\circ}$ flagelômeros; (6) $12^{\circ}$ e $13^{\circ}$ flagelômeros, apículo terminal; (7) palpo maxilar; (8) tórax; (9) asa; (10) terminália masculina, lateral; (11) terminália masculina, dorsal; (12) terminália masculina, ventral.

Sycorax chilensis difere das outras espécies neotropicais pelo tamanho maior. As quatro espécies colombianas e $S$. satchelli assemelham-se entre si pela presença de cerdas grossas (espinhos) no gonóstilo, característica não observada em $S$. bahiensis e $S$. assimilis. S. bahiensis diferencia-se de $S$. assimilis pelo formato do cerco e do parâmero. Em S. bahiensis o cerco é comprido, lateralmente de largura uniforme enquanto que em $S$. assimilis o cerco é lateralmente subesférico. O parâmero em $S$. bahiensis, lateralmente é largo, suboval e em $S$. assimilis é triangular, mais estreito no ápice.

\section{REFERÊNCIAS BIBLIOGRÁFICAS}

BARRETTO, M.P. 1956. Sobre o gênero Sycorax Hal., com as descrições de duas novas espécies do Brasil (Diptera, Psychodidae). Folia Clínica et Biológica, São Paulo, 26: 71-75.

Colles, D.H. \& D.K. McAlpine. 1991. Diptera, p. 717-786. In: CSIRO (Ed.). The insects of Australia. Victoria, Melbourne University Press, $1137 \mathrm{p}$.

Duckhouse, D.A.1972. Psychodidae (Diptera, Nematocera) of South Chile, subfamilies Sycoracinae and Trichomyiinae. 
Transactions of the Royal Entomological Society of London, London, 124: 231-268

Jezek, J. 1999. Comments on the correct grammatic gender of Sycorax Curt. and Philosepedon Eat. (Diptera: Psychodidae) with world catalogue. Dipterologica bohemoslovaca, Bratislava, 9: 83-87.

MCAlpine, J.F. 1981. Morphology and terminology: adults, p. 9-63. In: McAlpine, J.F.; B.V. Peterson; G.E. Shewell.; H.J.TesKey.; J.R. Vockeroth,. \& D.M. Wood (Eds). Manual of
Neartic Diptera. Ottawa, Research Branch, Agriculture Canada, Monograph \# 27, vol. 1, 674p.

TonNoIr, A.L. 1929. Diptera of Patagonia and south Chile. 2, Fascicle 1, Psychodidae. London, British Museum Natural History, 32p.

Young, D.G. 1979. A review of the bloodsucking psychodid flies of Colombia (Diptera: Phlebotominae and Sycoracinae). Gainsville, Technical Bulletin 806, IFAS, University of Florida, 226p.

Recebido em 13.II.2003; aceito em 06.VI.2003. 